continuous with the chin, there being no neck and no mental prominence. The head is thrown back on the shoulders, so that the face looks directly upwards; the ears lie on the suprascapular region, and the forehead in the same plane as the back. Fig. 2 shows the cranium to end at the posterior border of the frontal bone, where hair is found extending on to the shoulders. About the middle of the back there is a bony prominence $(A)$, and between this and the posterior border of the frontal bone a deep depression (B) exists covered by a thin membrane. Just below the prominence (A) there is a small opening (C) in the centre line, apparently the anus, which is not in its normal position, thus making the perineum of very abnormal length. The external genitals appear normal (female child), and the abdominal and thoracic walls are complete. The finger and toenails extend to the end of the digits, and there is no membrana pupillaris. The eyes are prominent and look directly upwards, and there are eyelashes on both lids.

On attempting to remove the calvarium it was found closely applied to the anterior portion of the base of the skull, which consisted of the sphenoid, petrous portion of temporal, and basilar portion of occipital, bone, apparently as far as the anterior border of the foramen magnum. On removing the membrane covering the depression (B) in the back, described before, a small amount of nervous matter was found, but with no definite form. The walls of the cavity were bony, and consisted below and behind of the vertebral column, and distorted ribs ending posteriorly in the prominence (A), the summit of which was found to be the last lumbar vertebra, where the spine appeared to end abruptly. The remaining vertebræ of the sacrum and coccyx were articulated almost at right angles, throwing the top of the coccyx directly forwards into the pelvis. The vertebræ consisted of a body and transverse processes, but no laminæ, nor could any spinal cord be found, but it seems likely that it was contained in the nervous matter found in the cavity described above, as the posterior surface of the vertebral bodies formed part of the posterior wall of the cavity.

Nothing of any interest was found on examining the internal organs beyond that there were two supernumerary spleens, and the large gut was found to communicate with the depression (c) in the back before referred to.

We are indebted to Dr. J. B. Stephenson (of Bristol), who was on a visit to the island at the time, for kindly assisting us in the dissection of the fotus.

\section{TWO CASES OF NEPHROLITHOTOMY}

ILLUSTRATING THE VALUE OF HEAVY PEROUSSION IN THE LOIN IN THE DIAGNOSIS OF RENAL OALCULUS.

BY W. F. BROOK, F.R.C.S., Senior Surgeon to the Swansea General:Hospital.

CASE I. A girl, aged 18, was first admitted into the Swansea Hospital in June, 1895 , for pain in the left iliac region of five years' standing. It was first confined to the periods of menstruation, but during the latter three years had commenced a week before the periods, and continued for three weeks. During the fourth week she was free from pain. When at its worst the pain was frequently associated with hysterical fits. She was entirely prevented from following her occupation - that of a domestic servant. On examination there was tenderness on pressure over and around the left ovary. Vaginal examination caused pain in the same region. There was no albumen in the urine. I was asked to see her by Dr. Knight, under whose care she was, with a view to exploring the left ovary. I did so on August 8th, found the ovary cystic, and removed it. The cyst contained about a drachm of fluid. The other ovary was healthy. After the operation she was free from pain for two months. It then returned and gradually became worse, but she had no fits. The abdominal pain was now more general, but was most severe about a point midway between the umbilicus and the anterior superior spine. It extended into the left flank, and deep pressure over the kidney caused pain,..but the seat of greatest tenderness corresponded to that of the greatest pain. Micturition was sometimes attended with dull heavy pain in the hypogastrium. "The urine contained occasionally a trace of albumen. Heavy percussion below the tip of the last rib caused acute stabbing pain in the loin. Albumen conld generally be found after a drive in a jolty conveyance, and the pain was worse during the night following these rides, but not at the time. She was readmitted on February 5 th of this year. I cut down on the kidney, and removed a large stone weighing 123 grains, a complete cast of the pelvis and calyces

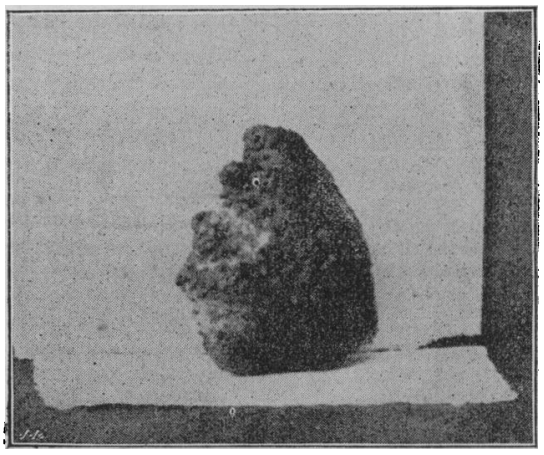

Fig. x.-Stone removed from Case I.

(Fig. 1). It consisted of oxalate of lime. The patient is now in service.

CASE II. The patient was a miner, aged 22. He was sent into hospital for supposed recurrent appendicitis. He was admitted on the medical side in September, 1894, and I was asked to see him with a view to removal of the appendix. There was a history of almost continuous pain for three years, of late getting so much worse that he had for many months been obliged to give up work. The pain, which was situated in the right iliac region, was most intense midway between the umbilicus and the anterior superior spine, where he also complained of great tenderness on pressure. The pain was worse after exercise, but was also very severe during absolute and continuous rest in bed. He was subject to constipation, and it was also worse when the bowels were confined. The only other symptom was a trace of albumen in the urine which, however, had not existed when looked for a short time before admission. This, in the absence of any lump in the right iliac fossa, led me to examine the right kidney. It was scarcely, if at all, more tender on deep palpation than the left, but heavy percussion immediately over the kidney in the back caused stabbing pain in the loin. When pressed for a history of urinary symptoms he admitted having sometimes passed urine which was " rather red," and some time previously having had a little pain in the end of the penis on making water. On cutting down on the right kidney a stone covered with needle-like crystals was removed from the

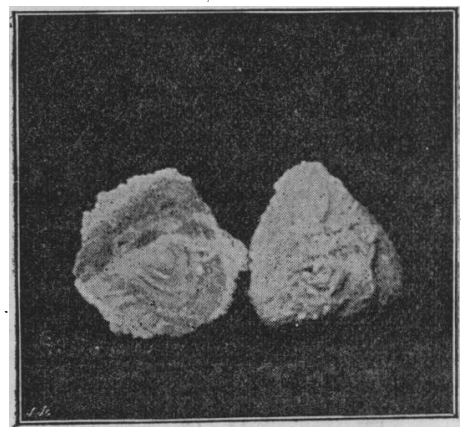

Fig, 2,-Stone removed from Case II.

pelvis (Fig. 2), though whether that was its original position or whether it was dislodged from a calyx at the time of operation I could not say. The stone consisted of oxalates and weighed 80 grains. The man returned to his work in the mine.

It is hardly necessary to draw attention to the similarity of the symptoms in both cases. The seat of most intense pain was the same, namely, McBurney's spot in one case and the corresponding spot on the left side in the other. In both there was almost an entire absence of the classical 
urinary symptoms of renal calculus. In each case the urine was repeatedly examined microscopically, but neither blood nor pus was ever found, although in each case the stone was rough and jagged and calculated to cause hæmaturia. In the absence of the acute stabbing pain on percussion in the loin it would have been impossible to have diagnosed a stone in either case. Mr. Jacobson, in his work on Operative Surgery, quotes Mr. Jordan Lloyd, who first drew attention to the symptom, as attaching great importance to it. I can, however, find no mention of it in any recent systematic work on surgery in the English language - a fact which seems strange considering the difficulties which frequently exist in the diagnosis of renal calculus. Its value when present may be immense, but its absence of course does not negative the existence of a stone. The important question, however, is whether the characteristic stabbing pain when present is diagnostic of stone. In vermiform trouble and impacted gallstone pain may be caused by heavy percussion in the loin, but in my limited experience the position and character have been very different.

[The notes of the first case were read at a meeting of the :South Wales Branch of the British Medical Association at Swansea, on September 24th. The second case was published in the Guy's Hospital Gazette about eighteen months ago by Dr. Floyd, then House Surgeon at the Swansea Hosmital.]

\section{ABSTRACT OF AN ADDRESS ON SOME MEDICAL QUESTIONS OF THE DAY.}

By H. W. KIALLMARK, M.R.C.S.,

Vice-President West London District, Metropolitan Counties Branch.

Mr. Kiallarark commenced his address by referring to the success which had attended the resuscitation of the District, and the holding of the meetings in the various parish infirmaries. He then proceeded to pass in review the more important medical topics of the past six months, referring first to skiagraphy and the Nauheim treatment of heart dis-ease. Continuing the subject of therapeutics, he said]:

The medication of zymotic diseases by antitoxic serums has been making rapid strides in all parts of the world; in recent times diphtheria, that terrible scourge, has been brought under the control of an antidiphtheritic serum with, it seems to me, striking success. On these points differences of opinion will always exist, but figures, illusory as they sometimes are, appear to point to a real improvement in the results of treatment. Encouraged by this success an attempt is being made to cope with other diseases -of a kindred type, such as those due to the presence of streptococei in the blood. Within the last few weeks cases have been reported of that terribly fatal disease-ulcerative endocarditis-having given way to injections of antistreptococcus serum. An antisyphilitic serum has also been brought to our notice, and a successful case of its use reported. ${ }^{2}$ It is remarkable that on the first introduction of a new remedy or a new line of treatment success is generally met with. Ten years later the whole thing is forgotten, possibly the name of the remedy. More than forty years ago, when I was a student syphilisation as practised by Boch, of Copenhagen, was held to be the future conqueror of syphilis, but who hears of syphilisation now? It was in some way analogous to the serum treatment, as it consisted in repeated inoculations of the syphilitic virus till immunity was obtained. During that somewhat long period, of innumerable new remedies introduced those that have survived could almost be counted on the fingers of one hand. Chloroform, the bromides, chloral, salicin, cocaine, podophyllin, and a few of the synthetic laboratory compounds remain; the rest, where are they? Calomel is still the best cholagogue, and mercury still the specific for syphilis.

As an instance of the survival of an old remedy I might cite to you the success which has recently attended the use of phosphate of soda in Graves's disease. Whilst referring to modern and even recent pharmacology I cannot omit a reference to the administration of animal extracts.

a Delivered at a meeting of the Metropolitan Counties Branch, West London District, November 20 th.

2 BRITish Mrdical JOURNAL, February 8th, 1896, Dr. H. S. Barling.
These are recommended in all and several organic complaints. In the list of a large wholesale druggist I find that the following are kept in stock: Thyroid gland, thymus gland, salivary gland, pineal gland, suprarenal capsule, cerebrin, didymin (?), pituitary body, bone medulla, spleen substance, ovarian substance, Fallopian tube substance, uterine wall substance, kidney, liver, lymphatic, pancreas, and synovia! Do not all these, if used, touch upon the heresy of similia similibus, and do they not remind us of the witches' broth as served up in Macbeth? To my old-fashioned and out-of-date mind there is much to regret and more to question in these modern modes. The worst of it is that these remedies, whose virtues are to be discovered, have vices which promptly show themselves.

Turning to the more strictly professional and political subjects of the day, we have had to welcome, after a seven years' delay, the advent of the report of the Vaccination Commission, which, by all of us who regard every unvaccinated individual as a source of possible danger to the community, must have been read with mingled feelings of surprise and even indignation. After proving up to the hilt that vaccination is the only means of stopping the spread of variola, and the one means of eventually stamping it out, the Commission in its wisdom recommends that it should no longer be compulsory, for the conscientious objectors will be numerous, and include all the faddists who look upon vaccination as an unwarrantable attack upon the liberty of the subject to spread a loathsome disease according to their own sweet will. Fortunately, the law still remains unchanged, and it is to be hoped will not be altered; it rests with the guardians and sanitary authorities to make it respected.

With regard to that still more burning question-the election of direct representatives - I am convinced that all the candidates are equally distinguished and capable. I venture to say, however, that it seems to me that those who are elected should at once devote all their endeavours to the task of enlarging the powers of the Council by further amendment of the Medical Act. Without such amendment the Council is powerless to increase its disciplinary action, or to deal with the thorny question of the registration of midwives. Lastly, as to the suggestion that has been made to the effect that the funds of the Association should be in part devoted to the purposes of medical defence, I am strongly at one with the opinion expressed by our President, Mr. Butlin, and hold that the Association has enough on its hands already if it adequately discharges its responsibilities. The dissensions of its individual members, or their grievances against others not in the profession, are well and successfully dealt with by the Medical Defence Union, and other societies of a like nature, to which most of us belong. It would be an evil day for the profession when our, so to speak, "trade disputes" became mixed up with the progress and high character of our noble art.

\section{STONE IN THE BLADDER : LITHOTOMY FOLLOWED BY LITHOLAPAXY.}

By SURGEON-MAJOR HAROLD HENDLEY, I.M.S., Civil Surgeon, Simla.

B., a Hindu, aged 36 , was admitted to the Dharmsala Civil Dispensary on June ist, 1896 , suffering from symptoms of stone in the bladder, which he described as having been present at least seven years. He stated that he had been operated upon for stone in 1889 , but that no stone was actually removed he professed, however, to have been free from discomfort for at least a year following. The hospital register revealed the fact that he had been operated upon on January gth, 1889, and that the operation was described as " incision for medical subordinate-in charge of the dispensary at that time-showed that, although he and the two surgeons present at the time of the operation were quite satisfied, after sounding, that a stone was present, none could be diecovered even after a thorough examination with the finger. In 1893 he was again admitted, and stone in the bladder was diagnosed without difficulty; in consequence, however, of his bad state of health-the result of cystitis-he was not operated upon. 